\title{
PERMANÊNCIA E SAÍDA DO CAMPO DE JOVENS ADULTOS NO OESTE CATARINENSE
}

\author{
CONTINUITY AND OUTPUT OF THE FIELD OF YOUNG ADULTS IN THE WEST OF SANTA \\ CATARINA
}

Jaíne Stein ${ }^{1}$, Ana Paula Risson², Anderson Luis Schuck³ , Álvaro Cielo Mahl ${ }^{4}$

RECEBIDO EM: 11/09/2018 | ACEITO EM: 06/03/2019

DOI: $10.5902 / 2317175835167$

\section{RESUMO}

A migração de jovens do campo para a cidade se estabelece como uma problemática social emergente, considerando as novas formas de produção na agricultura, as mudanças nas organizações familiares e as perspectivas de futuro. Diante deste cenário, esta pesquisa se propõe a analisar a permanência e saída de jovens adultos da região rural no oeste de Santa Catarina. Foram entrevistados oito sujeitos, divididos em dois grupos, sendo um formado por quatro jovens que permanecem no campo e o outro composto por quatro jovens que saíram. Todos participantes são filhos de agricultores e estudaram em uma Casa Familiar Rural (CRF) de um município do oeste catarinense. A coleta de dados foi feita através de entrevistas semiestruturadas, cujos discursos foram analisados no sentido das palavras, possibilitando uma compreensão do processo histórico da juventude rural neste contexto social. Pode-se identificar uma pluralidade de razões para a saída ou permanência dos jovens no campo, atravessadas por dinâmicas familiares, oportunidades sociais e de escolaridade e desejos de estabilidade financeira. Observa-se ainda a constituição de paradoxos que se referem à continuidade ou não no campo e sobre as condições de vida na cidade e no meio rural, que se alternam conforme as posições sociais e familiares, os aspectos psicológicos e as possibilidades de sociabilidade destes jovens.

Palavras-chave: Jovens rurais; Permanência no campo; Saída do campo; Psicologia.

\footnotetext{
1 Graduada em Psicologia

2 Psicóloga, graduada em Gestão de Pessoas, Mestra em Ciências da Saúde e Professora do curso de Psicologia da Universidade do Oeste de Santa Catarina (UNOESC). Possui experiência e como áreas de interesse: psicologia e políticas públicas, processos migratórios, saúde e imigração e políticas públicas de saúde.

3 Graduado em Psicologia (2010), com Pós Graduação em Saúde Mental - Ênfase em Dependência Química (2017) pela UNOCHAPECÓ. Mestre em Psicologia, na área de Práticas Culturais e Processos de Subjetivação pela UFSC (2017). Docente do curso de Psicologia da UNOESC Pinhalzinho e São Miguel do Oeste/SC. Tem experiência e possui como a área de interesse: psicologia e produção de subjetividade, sexualidade e populações vulneráveis.

4 Possui graduação em Psicologia pela Universidade Federal de Santa Catarina (2002) e mestrado em Psicologia do Desporto e do Exercício pela Universidade de Trás-os-Montes e Alto Douro (2005). Atualmente é professor da Universidade do Oeste de Santa Catarina (desde 2006) e coordenador do curso de Psicologia do Campus Aproximado de Pinhalzinho (desde 2012). Tem experiência e possui como a área de interesse: Psicologia do Esporte e do Exercício, Terapia Cognitivo-Comportamental e Orientação e Reorientação Profissional.
} 
JAÍNE STEIN, ANA PAULA RISSON, ANDERSON LUIS SCHUCK, ÁLVARO CIELO MAHL

\begin{abstract}
The migration of young people from the countryside to the city as established an emerging social problem, considering the new forms of production in agriculture, changes in family organizations and their prospects for the future. Against that background, this research proposes to analyze the continuity and output of the field, of young adults in the western region of Santa Catarina. It was interviewed eight subjects, divided into two groups, one group consisting of four young people who remain in the field and the other group composed of four young people who move out the field. All participants are children of farmers and studied in a Rural Family Home (CRF) of a municipality in the west of Santa Catarina. Data collection was done through semi-structured interviews, whose speeches were analyzed in the sense of words, enabling an understanding of the historical process of rural youth in this social context. One can identify a plurality of reasons for the output or continuity of young people in the countryside, crossed by family dynamics, social and educational opportunities and desires of financial stability. It is also observed the constitution of paradoxes that refer to the continuity or not in the countryside and on the conditions of life in the city and in the rural environment, which alternate according to the social and family positions, the psychological aspects and the sociability possibilities of these young.
\end{abstract}

Key-words: Rural youth; Continuity in the field; Output of the field, Psychology.

\title{
1 Introdução
}

O êxodo rural é o deslocamento de indivíduos do campo para as cidades e faz parte da história da humanidade. Este fenômeno geralmente ocorre porque as oportunidades sociais e econômicas no campo não atendem às expectativas de alguns habitantes. Os principais motivos que fazem com que grandes quantidades de pessoas saiam da zona rural para as grandes cidades são: busca de empregos com remuneração fixa, gastos insustentáveis com a mecanização da produção rural, desmotivação em decorrência das perdas com desastres naturais (secas, enchentes, etc.), procura por qualidade de ensino e necessidade de acesso aos serviços hospitalares e à educação. (SANDRONI, 2004).

O oeste de Santa Catarina, cenário desta pesquisa, possui significativa população rural e tem como uma de suas características o aglomerado de pequenos agricultores familiares. $\mathrm{O}$ crescimento populacional tem ficado abaixo da média do estado, o que significa um menor número de filhos por família, consequentemente uma diminuição de força de trabalho em atividades rurais. Estes agricultores estão vivenciando a saída de seus filhos do campo para estudar na universidade e/ou trabalhar em ocupações das mais variadas na cidade. Outra pequena parcela destes jovens permanece no campo e continuam com o trabalho já investido e iniciado pelos pais. No período de 2000 a 2010, o contexto rural do oeste catarinense perdeu 137.183 de seus habitantes, destacando-se deste contingente migratório, os jovens. (RENK; DORIGON; BAGNARA, 2014). 
Desde a criação da Política Nacional de Juventude (PNJ), em 2005, uma das diretrizes que guia a ação da Secretaria Nacional de Juventude (SNJ) é: os jovens devem ser reconhecidos como sujeitos de direitos e de políticas públicas. Para isso, é fundamental conhecer suas realidades, questões, opiniões e demandas, além das características sociais, demográficas, políticas e culturais que nos revelam o quadro geral das condições de vida da população juvenil no Brasil (CONJUVE, 2006). Ao abordar a realidade dos jovens no campo, considerando seu momento de desenvolvimento e o contexto histórico e cultural, se estabelecem questionamentos quanto à permanência na propriedade e consequente continuidade dos afazeres da família ou ao abandono da propriedade rural familiar buscando por melhores condições de vida nas cidades (DALCIN; TROIAN, 2009). Além disso, mesmo que o foco deste artigo não seja abordar o desenvolvimento rural, esta temática e a do êxodo da juventude estão intimamente interligadas, a medida que determinam o futuro da vida no campo.

As desigualdades e diferenciações que marcam o campo e a cidade são relevantes e impactam diretamente a vida das pessoas. Há desvalorização e inferioridade frente as pessoas do campo, especialmente em relação a criação de estratégias e políticas públicas específicas, e poucos incentivos para que os jovens permaneçam no campo. Desta forma, percebe-se que muitos jovens estão deixando o campo, suas origens e saberes, na tentativa de encontrar valorização de seu trabalho e melhoria na qualidade de vida em outro contexto.

Perceber esse novo "Brasil rural contemporâneo" é tirá-lo da invisibilidade e pensar em estratégias para o desenvolvimento rural e regional. Em decorrência deste contexto social, torna-se necessário uma investigação detalhada sobre o êxodo de jovens do campo, especialmente o que eles buscam com esta migração, quais são os fatores que levam os mesmos tomar a decisão de sair e quais são as influências de quem permanece no campo.

Diante deste contexto, o presente estudo, de abordagem qualitativa, realizado com quatro jovens que saíram do meio rural e quatro que permaneceram no campo, objetiva analisar a permanência e saída de jovens adultos do campo na região oeste de Santa Catarina. Assim, estima-se que esta pesquisa se integre a outros estudos que visam compreender o fenômeno do êxodo rural, especialmente o dos jovens, e que contribua com as reflexões em torno do desenvolvimento rural e local.

\section{0 êxodo rural de jovens}

O êxodo rural se estabelece em consequência da mecanização do campo, que impõe a saída de indivíduos do meio rural em direção ao meio urbano, englobando a busca de melhores condições de vida ou a compreensão de que o modo de vida na cidade seja menos sofrido. Dentre as motivações para esse deslocamento encontra-se a possibilidade de alcançar melhores perspectivas de futuro para suas famílias (SINGER, 1976). Outro fator relevante é a carência 
de investimentos voltados para a área rural, desestimulando o agricultor perante inúmeros problemas que precisa enfrentar com a insuficiência de subsídios do governo. Já os aposentados do meio rural migram para o meio urbano em busca de melhorias no acesso aos serviços, em razão de sua idade avançada (HERMES; VALENTE, 2006).

O êxodo dos jovens rurais é uma realidade presente no Brasil. Centenas deles migram de suas comunidades de origem para trabalhar ou estudar nas cidades e, na maioria das vezes, não voltam para a vida rural. Na questão das políticas públicas, é recente a preocupação de cuidar dos jovens moradores das áreas rurais do país. (CHAUVEAU, 2014). Ao pensar no processo de migração da juventude do campo, observa-se, inicialmente, a ocorrência de mudanças de perspectivas e planos que os pais têm frente ao futuro dos filhos jovens, podendo acarretar conflitos pelas formas distintas de pensamentos e sentimentos que os jovens e os pais têm perante o futuro da propriedade e da vida. As divergências de valores e crenças entre pais e filhos, coloca em risco a herança histórica e cultural da família sobre o construir uma vida no campo, "não existe atividade econômica onde as relações familiares tenham tanta importância como na agricultura". (SILVESTRO et al., 2001, p. 25).

Neste processo de decisão entre permanecer e sair do campo, nota-se que o jovem busca ocupar um papel com mais autonomia, participando das decisões econômicas e produtivas da propriedade. Apesar das condições favoráveis (como terra e maquinários), o estreitamento da relação entre pai e filho pode ocasionar na opção do jovem por sair, por uma dificuldade de relacionamento. Para Stropasolas (2002), abordar o contexto da juventude rural coloca em relevo este fenômeno como um problema em obter-se uma identidade social, uma vontade de afirmar a dignidade do lugar que se ocupa no mundo social, sua utilidade para os outros e o desejo de ser alguém.

As relações destas práticas sociais repercutem questionamentos sobre os projetos de vida, especialmente para os jovens. Um exemplo são as relações familiares, já que a influência da família no desenvolvimento vocacional, além de amplamente explorada, pode ocorrer em diferentes níveis e intensidades. Essa influência pode acontecer tanto de forma mais indireta, uma vez que a situação socioeconômica e cultural da família influencia as aspirações educacionais e profissionais de seus membros, quanto de forma mais direta, quando os pais conversam, incitam ou limitam claramente as opções ocupacionais de seus filhos (PIZZINATO et al., 2016). Entretanto, com os movimentos contemporâneos que tencionam as relações familiares e de gênero, há uma redefinição e um questionamento sobre os sistemas familiares no espaço rural na definição das aspirações profissionais destes jovens.

A partir do momento que o indivíduo se envolve com problemas no seu desenvolvimento pessoal, se torna mais difícil conciliar projetos de permanência no campo, pois nesta fase da vida eles estão planejando a realização de seus projetos pessoais, que são, muitas vezes, interrompidos pelas condições 
do núcleo familiar. Observa-se que, por conta das mudanças culturais, as relações entre pais e filhos tem se tornado mais democráticas e o que era imposto para os jovens passa a ser discutido (SPANEVELLO, 2005). Para além dos conflitos entre os projetos pessoais e familiares, a diminuição da mão de obra, as instabilidades climáticas, a redução da produtividade, as dificuldades de sucessão familiar no meio rural e a desvalorização do produto que eles produzem, podem estar entre os fatores que contribuem para a intensificação do êxodo rural para os jovens.

Em uma pesquisa realizada no oeste catarinense, Silvestro et al. (2001) constataram que "as moças deixam o campo antes e numa proporção muito maior que os rapazes". Nesta direção, Abramovay et al. (1998) compreendem que as relações sociais desiguais e excludentes presentes no interior da agricultura familiar pode ser considerada como um dos principais fatores responsáveis pela saída das mulheres do campo. Assim, longe de serem estáticas, as formas de compreender suas vivências e planejar a vida dos jovens nestes contextos configuram redes de significados e modos de subjetivação complexos, no qual as vivências subjetivas podem ser vistas como formas de interlocução dialógicas, em que emerge a noção de eu/nós/eles compartilhados de diferentes vozes, apropriações e reproduções discursivas (PIZZINATO et al., 2016).

Considerando as tendências migratórias, as visões e perspectivas dos jovens quanto à atividade agrícola, surge a necessidade de pesquisar aspectos positivos que favoreçam a sua permanência. Desse modo, tornam-se indispensáveis os estudos que analisam o modo de vida, as relações sociais, as condições estruturais, as oportunidades de lazer e acesso às atividades agrícolas e não agrícolas, para jovens de ambos os sexos (CARVALHO et al., 2009). Este cenário sinaliza para a necessidade de novos estudos em relação aos jovens rurais, vistas a criação e desenvolvimento das políticas públicas. Ainda entende-se que, para que a agricultura familiar continue exercendo o papel importante para o país, é necessário que estudos sobre a juventude rural sejam realizados, pois são eles os responsáveis pelo o futuro do setor e as eventuais mudanças que venham acontecer.

\section{Método de pesquisa}

Este estudo configura-se como uma pesquisa de campo de abordagem qualitativa. Esta maneira de pesquisar tem o intuito de descrever e analisar experiências através de reflexões, discutindo as vivências pessoais e coletivas. Pesquisas qualitativas têm como objetivo primordial a descrição das características de determinada população ou fenômeno, compreendendo os processos culturais e históricos que constituem os sujeitos e suas relações sociais (MINAYO, 2012; GIL, 2002).

O cenário de pesquisa foi um município do oeste catarinense, que possui em torno de 10 mil habitantes. Os participantes da pesquisa são filhos de agricultores e estudaram em uma Casa Familiar Rural (CRF) deste município. A CRF 
é uma associação que funciona como escola, em que o aluno fica uma semana em aula e a semana seguinte em casa, aplicando o que aprendeu. $O$ ensino desenvolvido é voltado para a realidade do campo e para a sucessão familiar, se estabelecendo como um incentivo para os alunos permanecerem no campo junto a suas famílias.

A seleção dos participantes ocorreu por meio da técnica snowball (bola de neve) em que os participantes iniciais indicam novos participantes, que por sua vez indicam novos participantes e assim sucessivamente, até que seja alcançado o objetivo proposto. Assim, participaram da pesquisa 8 jovens, com idades entre 18 e 25 anos, sendo 2 do sexo feminino e 6 do masculino. A fim de manter o sigilo e os cuidados éticos na pesquisa, os participantes foram identificados como: S.1, S.2, S.3, S.4 para os jovens que saíram do campo, e, P.1, P.2, P.3, P.4 os que permanecem no campo.

Como estratégia de coleta de dados foi utilizada uma entrevista semiestruturada. As entrevistas foram individuais, anônimas e gravadas com a concordância prévia dos entrevistados. Após leitura e assinatura do Termo de Consentimento Livre e Esclarecido (TCLE). Todo o conteúdo foi gravado em aparelho de áudio, para a melhor compreensão e aproveitamento. O projeto de pesquisa foi desenvolvido conforme as diretrizes da Resolução n. ${ }^{\circ}$ 466/2012, do Conselho Nacional de Saúde (CNS), para pesquisas realizadas em seres humanos, cumprindo as exigências da Comissão Nacional de Ética em Pesquisa (CONEP) e do Comitê de Ética em Pesquisa da UNOESC, sendo aprovado pelo parecer número 2.177.625/2017.

Para a análise e a interpretação dos dados foi utilizada a proposta de Eni Orlandi (2003) da análise de discurso. A autora ressalta que o discurso é como uma palavra em movimento, uma prática de linguagem, em que "procurase compreende a língua fazendo sentido, enquanto trabalho simbólico, parte do trabalho social geral, constitutivo do homem e da sua história" (p. 15). 0 trabalho com o discurso envolve, portanto, a construção de um dispositivo de interpretação dos ditos e não ditos, procurando ouvir o sujeito nos sentidos de suas palavras, a forma como este descreve e submete a análise os objetos simbólicos e ideológicos de sua realidade social.

Considerando os discursos dos entrevistados, o processo analítico buscou retratar como a história se faz presente na língua, em que as palavras são efeitos de discursos já realizados, imaginados ou possíveis (ORLANDI, 2003). Esse trabalho de análise permitiu a construção de três categorias que versam sobre a história dos jovens: 1) a decisão de permanecer ou sair do campo; 2) incentivos para permanecer no campo; 3) jovens rurais: relação com o mundo e perspectivas de futuro. Cada categoria representa um tópico de discussão, apresentados na sequência. 


\section{Apresentação e discussão dos resultados}

4.1 O processo de decisão do jovem: permanecer ou sair do campo?

Enquanto no passado o grande dilema era quais dos filhos herdaria a propriedade, hoje a questão é: haverá filhos dispostos em dar continuidade às atividades agropecuárias desenvolvidas pela família? No passado, permanecer no campo era uma obrigação dos filhos, na atualidade, passou a ser mais uma opção de vida (BONIATTI; FABRIS, 2017).

Stropasolas (2014, p. 148) compreende que "os agricultores vivem um paradoxo nas suas escolhas (...) divididos entre o desejo de ver seus filhos (as) colocados (as) na agricultura e no meio rural, seguindo a tradição de seus antepassados, e a necessidade de buscar alternativas melhores na cidade". O entendimento do autor está na direção da seguinte fala de um dos entrevistados: "Quando as propriedades são muito pequenas, não se torna viável a sucessão. Então, o pai prefere que o filho vai trabalhar na cidade e ele fica no campo trabalhando até se aposentar e depois vende a terra e vai para a cidade também" (P.2).

O acesso à uma renda própria é algo favorável no campo, entretanto, geralmente se torna um problema dentro da economia familiar, cujos recursos geralmente são indivisíveis e ficam sob o controle do pai (BRUMER, 2014). Quando há sofrimento dos pais em se manter no campo, com pouca terra e esperança, mostra-se um caminho que os filhos não devem seguir.

Considerando este cenário, uma alternativa para os jovens é o assalariamento no meio urbano, que marca uma ruptura temporária ou definitiva com a atividade agrícola, uma vez que eles podem decidir como utilizar os recursos. A autonomia financeira é sinalizada por $\$ .3$ como um motivador para sair do campo: "A família toda estava trabalhando em 10 hectares de terra e com as vacas de leite. Só que tinha um problema: 'pai, me dá dinheiro?'. Aí ele não dá. Eu queria comprar uma moto para sair. Hoje estou [trabalhando] na cidade e o dinheiro é meu!".

Constatou-se que as famílias dos participantes da pesquisa são compostas por 4 ou 5 pessoas, cuja dinâmica evidencia que se o irmão mais velho permanece no campo, fazendo com que o mais novo busque trabalho formal na cidade, ou vice-versa. Identifica-se ainda que, no caso das famílias que possuem quantidades de terras consideráveis e apoio dos pais para que os filhos permaneçam, há espaço para os filhos ficarem e trazerem seus companheiros para fazer a sucessão familiar, dando continuidade ao que os pais construíram. Esta realidade foi identificada percebida na fala do seguinte participante:

Na minha família tem quatro pessoas e aqui na propriedade trabaIhamos em cinco, no mês passado meu namorado passou a morar aqui. A família se entende bem, geralmente quando um propõe uma ideia sobre fazer uma coisa, algum investimento a gente senta, todos juntos e discute. Aí vemos se é viável ou não. (P. 4). 
No caso dos jovens participantes que saíram do campo, vale destacar que eles não se desligaram completamente dele. Importante considerar que, na realidade do oeste catarinense, muitos jovens, apesar de trabalharem na cidade, continuam morando na casa dos pais no campo, uma vez que se torna mais viável percorrer em torno de 2 a $9 \mathrm{~km}$ de distância por dia, do que residir completamente na cidade. Os participantes da pesquisa sinalizaram que residem há poucos quilômetros da cidade, facilitando o deslocamento rápido e prático até a cidade. Este contexto é diferente do mencionado por Dalcin e Troian (2009), no qual os jovens, por considerarem o campo longe de tudo, optaram por sair do campo.

Apesar de alguns participantes considerarem que morar no campo é uma melhor opção de vida, a cidade ainda se torna a escolhida, como expresso na seguinte fala: "Ah, na cidade é diferente. No interior é melhor, mas, eu saí do interior porque eu tive a oportunidade de trabalhar numa distribuidora, eu saí de casa com 18 anos" (S.1). Já para S.4: "Eu acho que a vida na cidade é uma forma mais fácil de vida, principalmente pela renda. No interior a qualidade de vida é melhor, mas a questão de renda não é garantida". Estas falas dos jovens rurais sinalizam os dilemas do trânsito entre o campo e a cidade.

A partir das falas dos participantes que saíram do campo entendemos que essa decisão é a expressão de seus questionamentos, redefinições sobre o mundo rural e de suas vidas, sendo que a satisfação do campo é ultrapassada pelas questões de estabilidade financeira e as limitações do tamanho da propriedade. Na mesma direção, Brumer (2014, p. 127) entende que, entre as principais mudanças que afetam os destinos dos jovens da agricultura familiar, estão: "a diminuição da taxa de fecundidade, o avanço da medicina que permitiu o prolongamento da vida humana, a universalização do acesso à educação (resultado da disponibilidade de transporte escolar e da legislação que impõe obrigatoriamente o ensino)". Destaca-se ainda a ampliação do acesso à seguridade social (aposentadoria rural e acesso à saúde) que contribui para a aproximação de direitos entre os que vivem no campo e na cidade.

As atividades de lazer da maioria dos jovens participantes que permanecem no campo e daqueles que já saíram são: jogar futebol com os amigos, participar de rodeios, bailes e ir jantar em restaurantes, exemplificado pela seguinte fala: "Não existe atividade de lazer só no campo ou só na cidade, é bom diversificar, não ia me satisfazer se meu lazer fosse só no campo ou só na cidade" (P.2). Os estudos de Carneiro (1998) mostram que os espaços de lazer são contrários do ambiente da rotina do dia a dia, ao se buscar descanso e prazer. No entanto, para os participantes desta pesquisa, tal aspecto pareceu influenciar na decisão da saída do jovem no campo.

Para cada estágio da vida familiar há um processo emocional de transição relacionado a como o jovem sai de casa, sendo que, para os que estão solteiros, isto implicará na aceitação da responsabilidade emocional e financeira, já em um casamento implicará o comprometimento com um novo sistema (CAMPOS, 
PERMANÊNCIA E SAÍDA DO CAMPO DE JOVENS ADULTOS NO OESTE CATARINENSE

2012). Assim, podemos perceber que há vários fatores emocionais envolvidos na saída ou permanência do jovem no campo. O participante P. 2 compreende que:

Hoje, a sucessão familiar, é difícil de acontecer nas famílias, porque geralmente o pai não valoriza o filho, não incentiva a ficar no campo, se queixa dos problemas, e instiga o filho a sair do campo. Isso é gerado consequentemente por não fazer o que se gosta. O pai, às vezes, está na agricultura porque é a única opção que ele tinha. Está trabalhando nisso a vida inteira, mas não gosta daquilo que faz e isso é uma pena. (P.2).

Na mesma direção, outro participante sinalizou a influência dos pais na sua decisão, mostrando nas entrelinhas que há um conflito interno entre sair e permanecer: "A mãe já vinha falando: 'melhor ir na cidade, vai ser melhor pra tu'. E eu fui com isso mesmo. Agora abri uma poupança pra guardar meu dinheiro pra no futuro ter uma vida mais tranquila" (S.3). Devido ao maior acesso à escolaridade, disseminação dos meios de comunicação em áreas rurais, de políticas públicas, da liberação cultural das regras aceitas pela tradição, da diminuição do número de filhos nas famílias, entre outros fatores, os projetos de vida dos jovens passam a se impor ao projeto dos pais (KISCHENER; KIYOTA; PERONDI, 2015).

As razões para a permanência e saída do campo são plurais. Para os participantes da pesquisa, os fatores que interferem diretamente na decisão de permanecer ou sair do campo referem-se: à procura por estabilidade financeira, conquistada por um trabalho assalariado na cidade, as limitações do tamanho da propriedade, os aspectos das condições de saúde, educação e lazer e fatores emocionais e sociais relacionados ao momento do ciclo de vida - juventude.

\subsection{Incentivos para permanecer no campo}

A partir do relato dos participantes, percebeu-se que aqueles que decidiram permanecer no campo possuem famílias com condições financeiras favoráveis para desenvolver as atividades agropecuárias, ou seja, possuem terra, capital e equipamentos adequados. Além de gostarem de trabalhar no meio rural, avaliam que a vida na cidade pode ser estressante e acreditam que o custo de vida no campo é menor do que o encontrado nos centros urbanos. Esta compreensão é exposta na fala abaixo:

Eu sempre tive essa vontade de ficar [no campo]. Quando eu estava na oitava série apareceu um cara da Casa Familiar na escola do interior onde eu estava estudando e fez a propaganda da casa e eu gostei por que eu já me interessava, queria ficar no campo. Deixei meus colegas de infância tudo para trás e fui. Aí com o tempo o pai começou a me incentivar, ele viu mesmo que eu queria. Aí o pai e a mãe começaram a investir na propriedade. A propriedade deu uma grande melhorada, cresceu bastante, não em tamanho, mas em produção em qualidade de vida. Aí 
eu me formei e eles já sabiam que eu queria ficar em casa, eu sempre demonstrei. O incentivo sempre foi do meu pai e da minha mãe que me deixaram livre pra escolher, e eu escolhi ficar na roça, na agricultura. (P.1).

Neste relato, percebe-se que a experiência da Casa Familiar Rural, um espaço de educação voltada para a dinâmica do campo, contribuiu para a permanência no meio rural, pois esta "expõe o jovem invariavelmente a novas ideias, tanto sobre o mundo como sobre os valores éticos e os direitos, distintas das ideias tradicionais de seus pais" (KISCHENER, KIYOTA, PERONDI, 2015, p.7). A mudança na concepção sobre o mundo possibilita um novo ambiente de convívio familiar, contribuindo para que muitos pais e dirigentes adultos valorizem a contribuição que os filhos podem dar, a partir dos conhecimentos que adquirem.

Os jovens participantes da pesquisa identificam como fundamentais os incentivos que recebem das políticas públicas e do município, como podemos perceber pela fala do entrevistado P.1: "Com relação aos incentivos das políticas públicas, do município e da cooperativa, nos disponibilizam um bom auxílio. Nos fornecem assistência técnica gratuita e todo o suporte necessário para que a gente". Apesar dos incentivos, ainda é notória a urgência na elaboração de políticas públicas mais eficazes, especialmente nas áreas de formação profissional direcionada ao campo, assistência técnica e infraestrutura para lazer e cultura, visto que tais fatores constituem as principais condições para a saída do campo. (CARVALHO et al., 2009)

Os jovens se reconhecem como parte do meio rural, mas expõem um desejo de reconhecimento das profissões ligadas ao campo, ao considerar que a sociedade ainda vê esse espaço como atrasado no âmbito tecnológico. Nesse sentido, cabe reafirmar o papel que as cooperativas assumem no contexto rural, desempenhando uma mediação no acesso e no avanço tecnológico aos jovens, suas famílias e população local. Tal avanço tecnológico é indispensável, pois, além do maior conforto doméstico e das facilitações nos processos produtivos, a tecnologia contribuiria com a valorização simbólica do espaço e das profissões tradicionalmente rurais (BOESSIO; DOULA, 2016). Nos valores sociais que fundamentam as cooperativas fica evidente o compromisso que as organizações assumem com seus cooperados e com a coletividade, no qual dois princípios recebem destaque: educação, formação, informação e preocupação com a comunidade.

Quanto a relação entre filhos e pais, apesar das dificuldades, os jovens reconhecem que também há modos de valorização do diálogo e reconhecimento, como visto na fala do entrevistado P.1: "Claro que não foi fácil. No começo sempre tinham um pé atrás, pois era um guri novo. Eles sempre queriam ter a última palavra e até hoje têm, mas sempre fazem uma consulta comigo sempre pedem pra mim como é melhor, como eu acho certo fazer". Algumas modificações na configuração das relações de poder podem ser observadas no contexto familiar. Silvestro et al. (2001) defendem, a partir de pesquisa 
realizada em Santa Catarina, que atualmente há o enfraquecimento do poder quase absoluto da figura paterna dentro da organização familiar tradicional rural. Esta mudança estaria abrindo espaço para a formação de um ambiente com maior participação de todos os membros da família, resultando em uma configuração mais "democrática". Contrariando tal perspectiva, Stropasolas (2011), com base em pesquisas também realizadas em Santa Catarina, ainda considera que, além dos conflitos gerados pelos diferentes interesses dentro do grupo familiar, um grande gerador de discordâncias é o modelo de gestão centralizado no pai e a grande dificuldade deste em aceitar inovações, geralmente propostas pelos filhos, nos processos gerenciais.

Os conflitos são vistos como elementos inevitáveis das relações, os quais podem desempenhar uma função positiva, principalmente quando resolvidos ou quando expressos de maneira construtiva (SILVA el al., 2012). A dificuldade de relacionamento intergeracional não está presente somente neste contexto de família rural, alterando constantemente o conceito sobre o novo e o velho, tornando as relações e decisões sobre o que é certo ou errado cada vez mais difícil. No entanto, como a dinâmica do trabalho da agricultura familiar é dividida entre os membros da família, os conflitos estão mais suscetíveis a acontecer, por conta deste compartilhamento de espaço, trabalho e dinâmica de vida. $\mathrm{O}$ apoio familiar é importante para a socialização dos filhos, pois, à medida que os pais mostram-se empáticos no que se refere a promoção de afeto, cuidados e conhecimento, eles são vistos pelos filhos como modelos positivos. Em contraponto, as emoções negativas e o sofrimento psicológico podem ter relação com um ambiente familiar menos apoiador, no qual os pais passam por situações estressoras e apresentam características de enfrentamento impróprias, o que aumenta a tendência dos filhos a apresentar baixa autoestima, aumento de ansiedade e sintomas depressivos (BAPTISTA; CARDOSO; GOMES, 2012).

Ainda, vale ressaltar que a maioria dos pais é da década de 1960 e os filhos de 1990, o que mostra historicamente subjetividades diferentes e condições de objetividade relacionadas às políticas públicas e sociais, cenário econômico e cultural que foram construídas de formas distintas. Como revela P.3: "Dava um conflito, por que eles pensavam que eu queria fazer as coisas [para contrariar eles], eles pensavam que era de um jeito e que eu queria fazer o contrário". A autonomia dada aos filhos pelos pais se mostra muito relevante nos fatores que incentivam a permanência no campo, provocadas mudanças nas relações familiares, que proporcionam uma participação maior de todos os trabalhadores familiares no processo de tomada de decisão, dando maior espaço para a atuação dos jovens (DALCIN; TROIAN, 2009).

\subsection{Jovens rurais: relação com o mundo e perspectivas de futuro}

Ao serem questionados sobre as perspectivas de futuro, a maioria dos jovens, tanto do campo como da cidade, pensam em se atualizar sempre atra- 
vés do estudo, além de expressarem a vontade de casar, ter filhos e construir sua moradia no campo, como podemos perceber pela fala de P.3: "Eu pretendo continuar sempre me especializando, pretendo me casar e continuar com minha família no campo". Já os jovens que saíram do campo pensam em, no futuro. Nunca se afastar deste ambiente, "Eu pretendo continuar trabalhando com vendas, não sei se vou ficar por muito tempo aqui. Pretendo continuar morando no interior e trabalhar na cidade! " (S.1).

Não se trata, no entanto, de uma percepção unilateral: o campo que exclui é, ao mesmo tempo, idealizado por ser aquele que oferece "melhor qualidade de vida, com menos poluição, alimentação mais saudável", mas é também um ambiente de adversidades, do trabalho "judiado, pesado, sem férias e de baixo rendimento". Os jovens encontram-se confrontados entre essas situações ambivalentes de melhor qualidade de vida no campo e a avaliação de um horizonte de poucas perspectivas futuras (ZAGO, 2016). Já os participantes da pesquisa que permanecem no campo têm uma visão de futuro próspero, onde quem ficar vai ser valorizado financeiramente, pois, poucos são os que ficam. Como podemos perceber na fala do participante P.1:

Eu acho que em alguns anos vai ter gente tentando buscar emprego no campo. Do jeito que estão as coisas na cidade, eu acho que vai ter essa volta dos filhos para casa ou alguma coisa assim. Os poucos que ficaram terão uma vida boa, farta, com uma boa qualidade de vida. (P. 1).

Para Junior (2007), as práticas e representações sociais dos jovens inseridos no meio rural, considerando seus contextos sociais, a relação entre campo e cidade, bem como seus projetos de vida, passam a ser tema de investigações quanto ao futuro destes sujeitos.

No meu ponto de vista, é melhor no campo. Eu já fiz uma experiência no meu estágio de morar na cidade. Permaneci na cidade um mês estudando e fazendo estágio e não me acostumei. Eu gosto do que eu faço, com certeza, se não eu não estaria hoje no campo. (P.4).

Sobre a questão dos estudos, dos oito participantes da pesquisa, dois que saíram do campo não mostraram interesse em continuar estudando, inclusive um jovem repensou sobre esta questão durante a entrevista quando foi perguntado o que ele gostaria de estudar: "Meu Deus! Eu nunca pensei nisso mesmo! Não vou saber te responder! " (S.3). Ainda pode-se perceber pelas falas dos participantes, sobre as perspectivas de futuro, uma incógnita (aquilo que se desconhece e se busca saber). Eles ficam surpresos ao refletirem sobre esse assunto, como expresso na fala de S.4: "O futuro, não sei! Eu pretendo trabalhar na área da enfermagem. Já estou ajuntada [amasiada] com o meu namorado, mas é praticamente casada". Já os que buscaram o estudo, se sentem obrigados 
pelo mercado de trabalho a buscarem se aperfeiçoar, como podemos perceber pela fala do entrevistado S.2: "Eu estou fazendo gestão ambiental, pra mim é bom. Se eu ficar aqui, eu uso no dia a dia. A gestão é o meu trabalho. E se um dia eu tiver a oportunidade de voltar de novo eu vou utilizar também".

Vale destacar que os entrevistados que permanecem no campo continuam estudando por incentivo de uma cooperativa como podemos perceber pela fala da participante P.4: "Primeiramente, eu queria fazer uma faculdade. Aí, meu irmão entrou na Casa Familiar e começou a trazer novidades. Aí eu comecei a me interessar e não quis ficar pra trás. Comecei a estudar também." Para Zago (2016), os jovens contam com outras influências proporcionadas pela expansão do ensino e pela maior flexibilização das fronteiras entre o rural e o urbano.

A oportunidade de continuar estudando permite aos jovens rurais novas perspectivas de vida pessoal e trabalho do campo. Observou-se que permanecer no campo não é sinônimo de parar de estudar. Além dos estudos na Casa Familiar Rural, os participantes da pesquisa sinalizaram a importância dos cursos oferecidos pelas cooperativas: "A gente precisa estudar. Nunca gostei de estudar, mas na Casa Familiar Rural eu me dediquei ao máximo. Nas outras escolas eu nunca tive vontade de estudar. Estou fazendo também os cursos que a cooperativa oferece. (P.1). "

A família vem igualmente passando por transformações, tanto no que diz respeito aos valores entre gerações quanto à perda de autonomia do agricultor diante da dependência ao capital financeiro e à agroindústria, enfrentando ainda incertezas quanto à sucessão da propriedade e ao futuro dos filhos (ZAGO, 2016). Tanto os jovens que permanecem quanto os jovens que saíram do campo demonstraram interesse em se casar e constituir uma família, representado nas seguintes falas:

Eu sempre gostei do campo, eu me criei no campo. Meu pai sempre deixou bem claro que a terra está lá se eu, um dia, quiser voltar e trazer minha família. Para nós é fácil por que do meu trabalho na cidade até na propriedade são dois quilômetros. É bem tranquilo, bem acessível. (S.2).

Eu pretendo me casar. Nunca vou deixar de estudar e buscar cursos para ir me aprofundando nos assuntos para ficar por dentro do que acontece. Não pode parar, todo ano muda algo. Eu quero continuar no campo e dar continuidade a o que meus pais começaram. (P. 3).

$\mathrm{Na}$ fala de um participante os relacionamentos conjugais também influenciam na tomada de decisão do jovem: "Eu estou namorando agora. A minha namorada é da cidade. Se eu falo alguma coisa do interior, ela já reclama. Isso também é um incentivo pra mim ficar na cidade" (S.3). Assim, ao mesmo tempo que se coloca o patriarcado como uma dificuldade de permanência no campo, no futuro, os jovens ainda se enxergam reproduzindo tal modelo de relações de poder. 
No ponto de vista financeiro os jovens participantes do estudo falam do lugar que estão vivendo, quem permanece no campo entende que é mais viável no campo, e quem saiu entende que há uma maior estabilidade financeira na cidade: "Eu acho que é no campo, pela questão de produção de alimentos por que tu produz mesmo e com isso tu reduz custos, é um pouco mais sofrido, mas é bem melhor do que na cidade" (P.3). Percebe-se, pela fala dos participantes, uma dicotomia em relação à questão financeira, pois em partes compreendem que é melhor no campo, já em outra dependendo do cargo seria melhor na cidade, como podemos perceber na seguinte fala:

Na parte financeira eu acho que depende muito do cargo que tu ocupa. Eu acredito que no interior a sobra [lucro] é menor, mas, a qualidade de vida é bem maior. Na agricultura tu não pode parar de investir se não tu para no tempo e tu perde mercado. Então, em épocas do ano ou quando o preço dos produtos está bom tu ganha um lucro maior. Só que eu acredito que a estabilidade financeira a agricultura é mais garantido que num emprego na cidade. Tu não sabe se amanhã pode ser demitido e não ter mais o emprego. E na agricultura provavelmente isso não vai mais acontecer, muito difícil uma propriedade quebrar de uma hora para outra. (P.1).

Nesta direção, mesmo os jovens que estão vivendo na cidade percebem que, em relação às perspectivas para o futuro, há uma maior dificuldade para se desenvolver na cidade, apesar do campo apresentar mais riscos, como é sinalizado por S.2: "No campo se corre mais riscos, mas a margem de lucro durante um ano inteiro é maior. Na cidade, por exemplo, você sempre vai trabaIhar por aquele salário. Na agricultura tu ainda pode melhorar isso ou aquilo, sempre fica acompanhando".

O abismo que havia entre a cidade e campo, hoje, tornou-se uma linha tênue onde as diferenças existentes não podem ser entendidas somente como um rural primitivo ou um urbano civilizado. Isto não significa também que este "novo rural" representa melhoria de vida para a totalidade da população do campo. Os jovens cultuam laços que os prendem ainda à cultura de origem, ao mesmo tempo em que percebem sua autoimagem refletida no espelho da cultura urbana. Estão situados em meio a uma cruzada que ainda os prende à família e à escola, entre o início da vida profissional e o casamento, entre a dependência e a autonomia econômica (PUNTEL; PAIVA; RAMOS, 2011). Vale reafirmar que as perspectivas de mundo e futuro são diferentes entre os participantes da pesquisa. Apesar disso ressalta-se que para os jovens que escolheram permanecer no campo, identificou-se que o estudo na Casa Familiar Rural e os cursos ofertados pelas cooperativas tem papel importante na decisão e permanência, bem como na construção de significados de estar neste local. 


\section{Considerações finais}

O maior incentivo para estes jovens permanecerem no campo refere-se ao apoio dos pais e ao interesse pela atividade e disponibilidade de terra. Já os fatores que influenciaram a saírem do campo compreendem, além das dinâmicas familiares, a expectativa de estabilidade financeira percebida na cidade.

A decisão entre sair ou permanecer no campo é tomada a partir da referência sobre a construção da história em que os pais desses jovens tiveram no campo. Observa-se que uma trajetória familiar assentada na realização com as atividades rurais incida à permanência de seus descendentes neste contexto. No entanto, situações em que esta vivência foi marcada por sofrimento com a vida no campo acabam por incrementar o desejo dos filhos de buscar alternativas.

Cria-se um paradoxo quando se toma por análise a avaliação que os jovens fazem da vida no campo, tanto os que decidem nele permanecer quanto os que optaram por sair. Essa contradição existe, pois ora alia-se a perspectivas que enaltecem a qualidade de vida neste espaço, por questões ambientais, associada à possibilidade de constituição familiar e profissional, permitindo também a continuidade dos estudos, ora atrela-se a aspectos negativos como aqueles relacionados à instabilidade financeira e dificuldades relacionadas ao trabalho agrícola.

Os limites que demarcam as fronteiras do mundo rural e urbano estão cada vez mais cooptados. Muitas mudanças ocorridas nos últimos anos potencializam o mundo no campo, não apenas como local de residência e onde se vive, mas também onde relações de trabalho são desenvolvidas. Nesta configuração, entrelaçam-se a vida familiar, a comunidade, a cidade e o campo - como local de trabalho. Não podemos entender estes locais como separados ou vinculados a uma análise de superposição, pois configuram-se em espaços dinâmicos que dão sentido à experiência de vida destes jovens e à sua própria inserção na sociedade. Assim, releva-se a necessidade de atenção sobre os modos e possibilidades de relação consigo (posição pessoal frente ao mundo) e a produção de subjetividades.

Considerar o jovem como um sujeito de sua história, talvez seja a primeira condição para que possam ser desenvolvidas políticas públicas que tragam respostas ao enfrentamento do êxodo de jovens do meio rural. Incluir o jovem para participar da construção de políticas públicas é um imperativo, pois, como sujeito de sua história, poderá contribuir efetivamente na solução dos problemas apresentados

\section{Referências}

ABRAMOVAY, Ricardo; SILVESTRO, M.; CORTINA, N.; BALDISSERA, I. T.; FERRARI, D.; TESTA, V. M. Juventude e agricultura familiar: desafio dos novos padrões sucessórios. Brasília: Unesco, 1998. 104 p.

BAPTISTA, Nunes Makilim; CARDOSO, Ferrari Hugo; GOMES, Oliveira Juliana. Intergeracionalidade familiar. In: BAPTISTA, Nunes Makilim. TEODORO, Maycoln L. M. (Orgs.). Psicologia de família: teoria, avaliação e intervenção. Porto Alegre: Artmed. 2012. p. 16-26. 
BOESSIO, Amábile Tolio; DOULA, Sheila Maria. Jovens rurais e influências institucionais para a permanência no campo: um estudo de caso em uma cooperativa agropecuária do Triângulo Mineiro. Campo Grande, Interações, v. 17, n. 3, p. 370-383, 2016. Disponível em: < http://www.scielo.br/pdf/inter/v17n3/15187012-inter-17-03-0370.pdf>. Aceso em: 05 dez. 2018.

BONIATTI, Marlene; FABRIS, Adilson José. Juventude rural no oeste catarinense. 2017. 28 f. Trabalho de Conclusão de Curso. Faculdades Itapiranga - FAl, Itapiranga, Santa Catarina, 2017. Disponível em: <http:// www.uniedu.sed.sc.gov.br/wp-content/uploads/2017/09/Marlene-Boniatti.pdf>. Acesso em: 05 dez. 2018.

BRUMER, Anita. As Perspectivas dos jovens agricultores familiares no início do século XXI. In: RENK, Arlene; DORIGON, Clovis (Orgs.). Juventude Rural, Cultura e Mudança Social. Chapecó: Argos, 2014. p. 115-138.

CAMPOS, Dinael Corrêa de. Saudade da família no futuro ou o futuro sem família? In: BAPTISTA, Nunes Makilim. TEODORO, Maycoln L. M. (Orgs.). Psicologia de família: teoria, avaliação e intervenção. Porto Alegre: Artmed, 2012. p. 74-86.

CARNEIRO, Maria José. Ruralidade: novas identidades em construção. Rio de Janeiro, Estudos Sociedade e Agricultura, v.1, n.11, p. 53-75, 1998. Disponível em: <https://revistaesa.com/ojs/index.php/esa/article/ download/135/131>. Acesso em: 27 out. 2018.

CARVALHO, Daniela Moreira et al. Perspectivas dos jovens rurais: campo versus cidade. In: $47^{\circ}$ Congresso Sociedade Brasileira de Economia Administração e Sociologia Rural. Porto Alegre. 2009. Disponível em: <www.sober.org.br/palestra/13/881.pdf>. Acesso em: 20 set. 2016.

CHAUVEAU, Hélene. O lugar do acesso (ou não acesso) ao lazer e á cultura na relação que os jovens rurais têm com seus territórios do interior catarinense. In: RENK, Arlene; DORIGON, Clovis (Orgs.). Juventude Rural, Cultura e Mudança Social. Chapecó: Argos, 2014. p. 99-114.

CONTI, Daniele Taíse. Estudo dos fatores de influência na migração rural/urbana no município de Horizontina. 2012. 29 f. Trabalho de Conclusão de Curso (Ciências Econômicas). FAHOR - Faculdade Horizontina. Rio Grande do Sul. 2012. Disponível em: <http://www.fahor.com.br/publicacoes/TFC/ Economia/2012/Daniele_Conti.pdf> Acesso em: 27 set. 2018.

CONJUVE. Conselho Nacional de Juventude et al. (Org.) Política nacional de juventude: diretrizes e perspectivas. São Paulo: Fundação Friedrich Ebert, 2006.

DALCIN, Dionéia; TROIAN, Alessandra. Jovem no meio rural a dicotomia entre sair e permanecer: um estudo de caso. In: I Seminário Nacional Sociologia e Política, 2009, Paraná. p. 1 - 20.

GIL, Antônio Carlos. Como elaborar projetos de pesquisa. 4. ed. Atlas: São Paulo. 2002.

HERMES, Clair Lisandra W.; VALENTE, Valdemar. Análise do Crescimento Populacional do Município de Agudo, RS, no período de 1970 a 2000. Revista Ciências Humanas, Santa Maria, v. 7, n. 1, p. 91-107, 2006. Disponível em: < http://sites.unifra.br/Portals/36/CHUMANAS/2006/crescimento.pdf>. Acesso em: 27 out. 2018.

JÚNIOR, H. P. C. Estudo da participação e permanência dos Jovens na agricultura familiar na localidade do ancorado em Rosário da Limeira - MG. 2007. 158 f. Dissertação (Meio Ambiente e Sustentabilidade). UNEC, Belo Horizonte, Minas Gerais. Disponível em: <http://bibliotecadigital.unec.edu.br/bdtdunec/tde_arquivos/22/ TDE-2008-03-04T063758Z-69/Publico/Dissertacao\%20-\%20Helio.pdf> Acesso em: 27 out. 2016.

KISCHENER, Manoel Adir; KIYOTA, Norma; PERONDI, Miguel Angelo. Sucessão geracional na agricultura familiar: lições apreendidas em duas comunidades rurais. Mundo Agrário, v. 16, n. 33, p. 01-17, 2015, Disponível em: <http://www.mundoagrario.unlp.edu.ar/article/view/MAv16n33a07>. Acesso em: 28 Mar. 2018.

MIRANDA, Lívia. Planejamento em Áreas de Transição Rural-Urbana: Velhas Novidades em Novos Territórios. Observatório das Metrópoles. Rio de Janeiro. 2007. Disponível em: <http://www. observatoriodasmetropoles.ufrj.br/Miranda_anpur_09.pdf> Acesso em: 27 out. 2016.

MINAYO, Maria Cecilia de Souza. Análise qualitativa: teoria, passos e fidedignidade. Rio de Janeiro, Ciência \& Saúde Coletiva, v.17, n.3, p. 621-626, 2012. Disponível em: <http://www.scielosp.org/pdf/csc/v17n3/v17n3a07>. Acesso em: 27 out. 2018.

ORLANDI, Eni Puccin. Análise de discurso: princípios e procedimentos. 5.ed. Campinas: Pontes, 2003.

PIZZINATO, Adolfo et al. Jovens mulheres do âmbito rural: gênero, projetos de vida e território em fotocomposições. Porto Alegre, Psicologia \& Sociedade, v. 28, n. 3, p. 473-483, 2016. Disponível em: < http://www.scielo. br/pdf/psoc/v28n3/1807-0310-psoc-28-03-00473.pdf>. Acesso em: 06 fev. 2019. 
PERMANÊNCIA E SAÍDA DO CAMPO DE JOVENS ADULTOS NO OESTE CATARINENSE

PUNTEL, Jovani Augusto; PAIVA, Carlos Águedo Nagel; RAMOS, Marília Patta. Situação e perspectivas dos jovens rurais no campo. In: I circuito de debates acadêmicos, 2011, Brasília. IPEA, p. 1-20. Disponível em: <http:// www.ipea.gov.br/code2011/chamada2011/pdf/area3/area3-artigo20.pdf>. Acesso em: 06 fev. 2019.

RENK, Arlene; DORIGON, Clovis; BAGNARA, Maritânia. Juventude Rural e Mudança Social. In: RENK, Arlene; DORIGON, Clovis (Orgs.). Juventude Rural, Cultura e Mudança Social. Chapecó: Argos, 2014. p. 77-98.

SANDRONI, Paulo. Novíssimo Dicionário de Economia. Editora Best Seller: São Paulo, 2004

SILVA, Costa da Souza Simone, et al. Família Ribeirinha: um estudo de suas relações. In: BAPTISTA, Nunes Makilim. TEODORO, Maycoln L. M. (Orgs.). Psicologia de família: teoria, avaliação e intervenção. Porto Alegre: Artmed, 2012. p. 88-99.

SILVESTRO, Milton Luiz et al. Os impasses da sucessão hereditária na agricultura familiar. Florianópolis, SC: Epagri/Nead/Ministério do Desenvolvimento Agrário, 2001. p. 1-120.

SINGER, Paul. Dinâmica populacional e desenvolvimento. 2. Ed. São Paulo: Hucitec, 1976.

SPANEVELLO, Rosani Maria; Jovens rurais do município de nova Palma RS, situação atual e perspectivas. Redes, Santa Cruz do Sul, v.10, n.1, p.171-189, 2005. Disponível em: <https://online.unisc.br/seer/index.php/redes/ article/viewFile/11039/pdf>. Acesso em: 27 out. 2018.

STROPASOLAS, Luiz Valmir. Os dilemas da juventude no processo sucessório da agricultura familiar. In: RENK, Arlene; DORIGON, Clovis (Orgs). Juventude Rural, Cultura e Mudança Social. Chapecó: Argos, 2014. p. 139162.

Os desafios da sucessão geracional na agricultura familiar. Revista Agriculturas. v. 8, n. 1, p. 26-29. Rio de Janeiro. 2011. Disponível em: <http://aspta.org.br/wp-content/uploads/2011/08/artigo-5.pdf> Acesso em: 25 out. 2017.

O mundo rural no horizonte dos jovens: o caso dos filhos (as) de agricultores familiares de Ouro/ SC. 2002. 288 f. Tese de Doutorado. (Ciências Humanas, Sociedade e Meio Ambiente). Universidade Federal de Santa Catarina - UFSC, Florianópolis. Disponível em: <https://repositorio.ufsc.br/bitstream/ handle/123456789/82617/184359.pdf?sequence=1>. Acesso em: 26 out.2017.

ZAGO, Nadir. Migração rural-urbana, juventude e ensino superior. Chapecó, Revista Brasileira de Educação, v. 21, n. 64, p. 61-78, 2016. Disponível em: <http://www.scielo.br/pdf/rbedu/v21n64/1413-2478rbedu-21-64-0061.pdf>. Acesso em: 12 fev. 2019. 